\title{
КЛАССИФИКАЦИЯ И АПРОБАЦИЯ ПОКАЗАТЕЛЕЙ ДЛЯ СОВЕРШЕНСТВОВАНИЯ МЕТОДИКИ ОЦЕНКИ УСТОЙЧИВОГО РАЗВИТИЯ УГЛЕДОБЫВАЮЩИХ ПРЕДПРИЯТИЙ
}

\author{
(C) 2019 Лютягин Дмитрий Владимирович
}

кандидат экономических наук, доцент кафедры экономики минерально-сырьевого комплекса Российский государственный геологоразведочный университет им. Серго Орджоникидзе (МГРИ-РГГРУ), Россия, Москва E-mail: 1-d-v@list.ru

\section{(c) 2019 Сорокина Виктория Викторовна}

студент магистратуры по направлению подготовки 38.04.01 «Экономика» Российский государственный геологоразведочный университет им. Серго Орджоникидзе (МГРИ-РГГРУ), Россия, Москва

Данная статья посвящена исследованию показателей, оценивающих устойчивое развитие угледобывающих предприятий. В статье автором проанализированы существующие подходы к оценке эффективности деятельности предприятий угледобывающей отрасли, выделены их достоинства и недостатки. По результатам исследования автором разработана система показателей, характеризующих устойчивость развития угледобывающего предприятия с учетом таких составляющих как: финансовая; экономическая; социальная; производственно-техническая; экологическая. Для апробации предложенных показателей был использован метод таксономического анализа, позволяющий оценить уровень эффективности работы в динамике на примере ПАО «Распадская». Усовершенствованная методика оценки устойчивого развития угледобывающих предприятий может стать базисом для формирования комплексных программ стратегического развития, как предприятия, так и отрасли в целом.

Ключевые слова: угледобывающие предприятия, устойчивое развитие, эффективность, индикаторы, таксономический показатель.

Минералы являются необходимым сырьем во многих отраслях промышленности, однако добыча и переработка полезных ископаемых связаны с рядом проблем, препятствующих устойчивому развитию добывающего сектора, и обуславливают необходимость решения различных экономических, экологических и социальных вопросов. С одной стороны угольная отрасль является источником занятости и создания материальных благ. С другой стороны, добыча угля неизменно приводит к различным воздействиям на окружающую среду, включая истощение невозобновляемых ресурсов, нарушение ландшафта и угрозу для здоровья и безопасности работников и населения. В связи с этим актуализируется вопрос о целесообразности работы ряда предприятий угледобывающего сектора, что требует расчета показателей не только их финансовой устойчивости, но и отражающих их влияние на экологию и социальную среду. Идентификация таких показателей является одной из важнейших функций менеджеров на предприятии и необходимым условием устойчивого раз- вития, как отдельного предприятия, так и угледобывающей отрасли в целом.

Проведенное исследование литературных источников свидетельствует о том, что, преимущественно, внимание исследователей сосредоточено на выявлении факторов, влияющих на деятельность угледобывающих предприятий. Среди них обозначим труды таких ученых как: Т.Н. Тополева, И.Р. Руйга, Т.В. Зюбанова, Е.В. Яроцкая, А.А. Потапова, Deborah J. Shields, Яковлев В.Л., Кравчук И.Л. и др. Однако, обоснованию и формированию системы показателей, характеризующих эффективность деятельности угледобывающих предприятий в контексте их финансового состояния, влияния на экологию, удовлетворения социальных проблем, уделяется недостаточно внимания, что и актуализировало тему исследования.

Целью исследования является формирование обоснованного перечня и классификация показателей для совершенствования методики оценки устойчивого развития угледобывающих предприятий. 
В настоящее время эффективность работы предприятия, в основном, определяется с помощью методик оценки уровня банкротства, которых разработано за последние десятилетия огромное множество. В тоже время, некоторые исследователи ставят под сомнение универсальность большинства моделей, и предлагают ряд методик, учитывающих отраслевую принадлежность компании. Так, например, А.В. Казакова и А.В. Колышкина (Россия) [1] разработали модель оценки банкротства для предприятий торговли и услуг, Е.А. Федорова и С.Е. Довженко (Россия) - для отраслей обрабатывающей промышленности [2], Е.А. Федорова и Я.В. Тимофеева (Россия) [3] предложили методики для сельскохозяйственных и строительных предприятий, М. Буткус, С. Жакаре, Д. Чибульскене (Литва) [4] - для индустриальных компаний, Ткач Е.С., Ханафиева Ю.Д. и Чекушина И.А. (Россия) - для нефтегазовой отрасли [5], а Жданов В.Ю. и Афанасьева О.А. (Россия) - для авиапредприятий [6]. Тем не менее, общим недостатком указанных моделей является то, что все они отражают только финансовую составляющую работы предприятия и не учитывают особенности угледобывающей отрасли.

Chaodong Yan, Hongjun Dai и Wen Guo в своем исследовании предложили ряд показателей для оценки уровня загрязнения окружающей среды в результате воздействия угледобывающих компаний [7]. Авторы выделили 19 показателей, разбив их на 4 категории: 1) индикаторы, характеризующие состояние земельных ресурсов; 2) индикаторы, характеризующие состояние водных ресурсов; 3) индикаторы, отражающие количество отходов; 4) индикаторы, характеризующие уровень шума и загрязнения воздуха.

Основным недостатком данной методики является то, что в ней анализируется только экологическая составляющая работы предприятия, что не позволяет сделать полноценные выводы об эффективности его работы. Более того, информацию для расчета предложенных коэффициентов (например, РН поверхностных вод, индекс загрязненности отходов, среднее содержание диоксида серы и др.) отечественные предприятия не предоставляют.

C. Lins, E. Horwitz [8] охватывают 3 категории показателей, каждая из которых включает подгруппы индикаторов, на основании которых можно оценить эффективность деятельности добывающих предприятий. Авторы выделяют следующие группы индикаторов: 1) экологические (оценка качества менеджмента окружающей среды; изменение климата; водный менеджмент); 2) социальные (безопасность сотрудников и общества; взаимодействие с заинтересованными сторонами; сокращение ВИЧ / СПИДа; политика жизненного цикла; права человека; развитие сообщества; система управления цепочками поставок); 3) экономические /правительственные (уровень прозрачности и ответственности компании; внешние показатели эффективности; отраслевые / глобальные инициативы). Более того, каждая подгруппа включает в себя еще ряд показателей. Интерес представляют показатели, характеризующие безопасность сотрудников, права человека, уровень прозрачности и ответственности компании. К сожалению, формулы расчета показателей исследователи не приводят, также большинство показателей являются качественными (например, свобода политики объединения, консультации с заинтересованными сторонами, использование стандартов AA1000AS, политика изменения климата и др.), что снижает качество полученной оценки.

В свою очередь Deborah J. Shields [9] классифицирует индикаторы оценки устойчивого развития предприятий угледобывающего сектора на 4 категории: 1) производственные (оценка ресурсов, разведочные и добывающие мощности, использование энергии); 2) социально-экономические (уровень доходов и расходов в регионе и стране, культурные, социальные и духовные потребности, капитал); 3) институциональноправовые (правовая база, институциональные рамки, способность проводить и использовать исследования и разработки); 4) экологические (уровень мелиорации, экологические выбросы и др.). Основным недостатком данного подхода является то, что автор не раскрывает методологию расчета показателей, относящихся к каждой группе. Также не совсем понятным является влияние таких показателей, как культурные и духовные потребности населения на эффективность работы предприятия.

Значительный интерес представляет классификация показателей оценки эффективности угледобывающих предприятий, разработанная отечественным исследователем Комиссаровой М.А. [10]. Она предложила 5 групп коэффициентов, включающих 29 показателей, к которым относятся: 1) финансовая составляющая; 
2) клиентская составляющая; 3) группа коэффициентов, отражающая внутренние процессы; 4) обучение и развитие; 5) рациональное природопользование. В отличие от предыдущих исследований, автор учитывает финансовое состояние предприятия, однако часть показателей являются спорными. Так, например, учитывая специфику отрасли, не совсем понятно, насколько сильно на эффективность работы предприятия влияет показатель, характеризующий число специалистов с высшим образованием. Также часть индикаторов (например, сроки поставки, коэффициент обновления норм, доля постоянных покупателей и др.) внешнему пользователю невозможно рассчитать, поскольку необходимые данные в свободном доступе отсутствуют. Дублирующими показателями являются также показатели текучести и постоянства кадрового состава, коэффициенты покрытия и текущей ликвидности, совокупный природный потенциал и уровень использования совокупного потенциала. В связи с этим актуализируется вопрос об усовершенствовании системы показателей, оценивающих эффективность функционирования угледобывающих предприятий.

В целом, следует отметить, что все рассмотренные подходы к оценке устойчивого развития предприятия угледобывающего сектора базируются, прежде всего, на факторах, оказывающих влияние на эффективность их работы.

Резюмируя наработки исследователей по данной теме, для оценки эффективности работы угледобывающего предприятия предлагается следующая система показателей [5; 7-10]:

1. Финансовая составляющая:

1.1) коэффициент автономии;

1.2) коэффициент финансового риска;

1.3) коэффициент текущей ликвидности;

1.4) рентабельность продукции;

1.5) коэффициент обеспеченности собственными оборотными средствами;

1.6) рентабельность активов;

1.7) доля транспортных расходов в прибыли.

2. Экономическая составляющая:

2.1) рыночная доля компании на рынке (\%);

2.2) уровень инфляции (\%).

3. Социальная составляющая:

3.1) инвестиции на охрану здоровья и безопасность сотрудников (\%) - определяются как доля расходов на охрану здоровья, страховую защиту, материальную помощь и др. социальные расходы в чистой прибыли предприятия;

3.2) инвестиции в человеческий капитал (\%)
- представляют собой расходы на оплату труда и обучение персонала по отношению к чистой прибыли;

3.3) количество фатальных случаев на работе (отражает уровень безопасности условий труда горняков);

3.4) число сотрудников (отражает уровень постоянства кадрового состава).

4. Экологическая составляющая:

4.1) показатель ресурсоотдачи;

4.2) уровень защиты окружающей среды (\%) - отражает сумму расходов предприятия на природоохранные мероприятия по отношению к чистой прибыли.

5. Производственно-технические показатели:

5.1) коэффициент износа - демонстрирует степень изношенности основных фондов предприятия;

5.2) объемы добычи угля (тыс. тонн);

5.3) проходка выработок (м);

5.4) производительность труда рабочего по добыче (т/чел.) в месяц;

5.5) производительность труда рабочего на подготовительных работах (м/чел.) в месяц;

5.6) энергоемкость производства - отражает расходы предприятия на потребление энергоресурсов из расчета на единицу продукции (руб./т).

Предложенную систему показателей предлагается апробировать на угольном предприятии ПАО «Распадская» за 2016-2018 гг. В качестве метода оценки эффективности деятельности предприятия будет использован таксономический анализ, который позволяет сопоставить многомерные объекты во времени. Методика построения интегрального показателя путем использования метода расчета таксономического коэффициента отображена в [11].

Оценка эффективности деятельности компании включает ряд этапов.

1. Формирование матрицы наблюдений (табл. 1) и дифференциация ее переменных на стимуляторы (оказывающие положительное влияние на общий уровень развития объекта) и дестимуляторы (сдерживающие развитие).

2. Формирование матрицы стандартизованных значений (табл. 2) по формуле:

$$
Z_{i j}=\frac{X_{i j}}{X_{\text {cp } . j}}
$$

$X_{i j}$ - значение показателя ј в период времени і.

$X_{c p . j}-$ среднее значение показателя. 
Таблица 1. Показатели эффективности деятельности ПАО «Распадская»

\begin{tabular}{|c|c|c|c|c|c|}
\hline № $\Pi / \Pi$ & Показатели & $\begin{array}{l}\text { Стимулятор/ } \\
\text { дестимулятор }\end{array}$ & 2016 & 2017 & 2018 \\
\hline 1 & коэффициент автономии; & стимулятор & 0,23 & 0,49 & 0,61 \\
\hline 2 & коэффициент финансового риска; & дестимулятор & 3,28 & 1,03 & 0,64 \\
\hline 3 & коэффициент текущей ликвидности; & стимулятор & 0,23 & 0,98 & 1,60 \\
\hline 4 & рентабельность продукции & стимулятор & 2,01 & 0,78 & 0,93 \\
\hline 5 & коэффициент обеспеченности ВОК; & стимулятор & $-1,89$ & $-0,15$ & 0,30 \\
\hline 6 & рентабельность активов; & стимулятор & 0,23 & 0,24 & 0,26 \\
\hline 7 & доля транспортных расходов в себестоимости & дестимулятор & 0,02 & 0,01 & 0,01 \\
\hline 8 & доля сегмента рынка,\% & стимулятор & 2,72 & 2,78 & 2,90 \\
\hline 9 & уровень инфляции,\% & дестимулятор & 5,40 & 2,50 & 4,30 \\
\hline 10 & инвестиции в здоровье и безопасность,\% & стимулятор & 1,22 & 0,88 & 1,40 \\
\hline 11 & инвестиции в человеческий капитал,\% & стимулятор & 11,54 & 8,67 & 13,91 \\
\hline 12 & количество фатальных случаев на работе, ед. & дестимулятор & 0,00 & 0,00 & 1,00 \\
\hline 13 & число сотрудников, чел. & стимулятор & 2250,00 & 2134,00 & 2072,00 \\
\hline 14 & ресурсоотдача & стимулятор & 0,22 & 0,66 & 0,63 \\
\hline 15 & уровень защиты окружающей среды,\% & стимулятор & 0,05 & 0,12 & 0,39 \\
\hline 16 & коэффициент износа; & дестимулятор & 0,02 & 0,07 & 0,08 \\
\hline 17 & объемы добычи угля, тыс. тонн & стимулятор & 10512 & 11435 & 11950 \\
\hline 18 & проведение выработок, м & стимулятор & 17627 & 23258 & 19235 \\
\hline 19 & $\begin{array}{l}\text { производительность труда рабочего по добыче } \\
\text { (т/чел.) в месяц }\end{array}$ & стимулятор & 1155,00 & 1369,00 & 1290,00 \\
\hline 20 & $\begin{array}{l}\text { производительность труда рабочего на подгото- } \\
\text { вительных работах (м/чел.) в месяц }\end{array}$ & стимулятор & 2,18 & 2,92 & 2,56 \\
\hline 21 & энергоемкость производства (руб/т) & дестимулятор & 107,29 & 111,70 & 132,93 \\
\hline
\end{tabular}

Источник: рассчитано автором по данным [12-14]

Таблица 2. Матрица стандартизованных значений

\begin{tabular}{|c|c|c|c|c|c|c|c|c|c|c|c|}
\hline \multirow{2}{*}{ Период } & \multicolumn{11}{|c|}{ Показатели } \\
\hline & 1 & 2 & 3 & 4 & 5 & 6 & 7 & 8 & 9 & 10 & 11 \\
\hline 2016 & 0,52 & 1,99 & 0,24 & 1,62 & 3,26 & 0,94 & 2,02 & 0,97 & 1,33 & 1,05 & 1,01 \\
\hline 2017 & 1,11 & 0,62 & 1,05 & 0,63 & 0,26 & 1,00 & 0,54 & 0,99 & 0,61 & 0,75 & 0,76 \\
\hline 2018 & 1,37 & 0,39 & 1,71 & 0,75 & $-0,52$ & 1,07 & 0,44 & 1,04 & 1,06 & 1,20 & 1,22 \\
\hline$X_{c p . j}$ & 0,45 & 1,65 & 0,94 & 1,24 & $-0,58$ & 0,24 & 0,01 & 2,80 & 4,07 & 1,17 & 11,38 \\
\hline \multirow{2}{*}{ Период } & \multicolumn{11}{|c|}{ Показатели } \\
\hline & 12 & 13 & 14 & 15 & 16 & 17 & 18 & 19 & 20 & \multicolumn{2}{|c|}{21} \\
\hline 2016 & 0,00 & 1,05 & 0,45 & 0,26 & 0,38 & 0,93 & 0,88 & 0,91 & 0,85 & \multicolumn{2}{|c|}{0,91} \\
\hline 2017 & 0,00 & 0,99 & 1,30 & 0,12 & 1,30 & 1,01 & 1,16 & 1,08 & 1,14 & \multicolumn{2}{|c|}{0,95} \\
\hline 2018 & 3,00 & 0,96 & 1,25 & 2,12 & 1,33 & 1,06 & 0,96 & 1,01 & 1,00 & \multicolumn{2}{|c|}{1,13} \\
\hline$X_{c p . j}$ & 0,33 & 2152 & 0,5 & 0,18 & 0,06 & 11299 & 20040 & 1271,33 & 2,55 & \multicolumn{2}{|c|}{117,31} \\
\hline
\end{tabular}

Источник: рассчитано автором 
3. Построение эталона развития $\mathrm{Z}_{0}$. Элементы этого вектора имеют координаты $Z_{\text {оi }}$ и формируют значения показателей следующим образом:

$$
\begin{aligned}
& \left\{Z_{o i}={ }_{\text {max }} X_{i j}-\right.\text { стимулятор; } \\
& \left\{Z_{o i}={ }_{\text {min }} X_{i j}-\right.\text { дестимулятор; }
\end{aligned}
$$

4. Построение матрицы расчета расстояния между отдельными наблюдениями (период) и вектором-эталоном:

$$
\mathrm{C} \text { io }=\sqrt{\sum_{j=1}^{m}(\mathrm{Zij}-\mathrm{Zoj})^{2}}
$$

где Zij - стандартизованное значение j-го показателя в период времени i;

Zoj - стандартизованное значение j-го показателя в эталоне.

5. Расчет среднего расстояния между наблюдениями:

$$
\overline{\mathrm{C}_{0}}=\frac{1}{m} \sum_{i=1}^{m} C_{i 0}
$$

6. Расчет стандартного отклонения (S0), максимально возможного отклонения от сведенного эталона (C0), сведенного динамическо- го показателя уровня развития (di):

$$
\begin{aligned}
S_{0} & =\sqrt{\frac{1}{m} \sum\left(C_{i 0}-\bar{C}_{0}\right)^{2}} \\
C_{0} & =\bar{C}_{0}+2 S_{0} \\
d_{i} & =\frac{C_{i 0}}{C_{0}}
\end{aligned}
$$

7. Расчет таксономического коэффициента развития (Ki):

$$
K_{i}=1-d_{i}
$$

Значение таксономического показателя развития может находиться в пределах от 0 до 1 $(0 \leqslant \mathrm{~K} \leqslant 1)$, чем выше значение показателя, тем эффективнее работает предприятие.

Полученные результаты по ПАО «Распадская» свидетельствуют о том, что компания в 2016-2018 гг. была далека от эталонного показателя (рис. 1). Наиболее эффективно с учетом

\begin{tabular}{|c|c|c|c|c|c|c|c|c|c|c|c|}
\hline \multirow{2}{*}{ Период } & \multicolumn{11}{|c|}{ Показатели } \\
\hline & 1 & 2 & 3 & 4 & 5 & 6 & 7 & 8 & 9 & 10 & 11 \\
\hline 2016 & 0,00 & 2,56 & 2,15 & 0,00 & 14,34 & 0,02 & 2,52 & 0,00 & 0,51 & 0,02 & 0,04 \\
\hline 2017 & 0,34 & 0,06 & 0,44 & 0,99 & 0,62 & 0,01 & 0,01 & 0,00 & 0,00 & 0,20 & 0,21 \\
\hline 2018 & 0,71 & 0,00 & 0,00 & 0,77 & 0,00 & 0,00 & 0,00 & 0,00 & 0,20 & 0,00 & 0,00 \\
\hline \multirow{2}{*}{ Период } & \multicolumn{11}{|c|}{ Показатели } \\
\hline & 12 & 13 & 14 & 15 & 16 & 17 & 18 & 19 & 20 & \multicolumn{2}{|c|}{21} \\
\hline 2016 & 0,00 & 0,00 & 0,73 & 3,45 & 0,00 & 0,02 & 0,08 & 0,03 & 0,08 & \multicolumn{2}{|c|}{0,00} \\
\hline 2017 & 0,00 & 0,00 & 0,00 & 4,01 & 0,84 & 0,00 & 0,00 & 0,00 & 0,00 & \multicolumn{2}{|c|}{0,00} \\
\hline 2018 & 9,00 & 0,01 & 0,00 & 0,00 & 0,90 & 0,00 & 0,04 & 0,00 & 0,02 & \multicolumn{2}{|c|}{0,05} \\
\hline
\end{tabular}
предложенных составляющих предприятие функционировало в 2017 г., когда значение таксономического показателя составило 0,52, наи-

Таблица 2.1. Матрица значений эталона развития

\begin{tabular}{|c|c|c|c|c|c|c|c|c|c|c|c|}
\hline \multirow{2}{*}{ Период } & \multicolumn{10}{|c|}{ Показатели } \\
\cline { 2 - 12 } & $\mathbf{1}$ & $\mathbf{2}$ & $\mathbf{3}$ & $\mathbf{4}$ & $\mathbf{5}$ & $\mathbf{6}$ & $\mathbf{7}$ & $\mathbf{8}$ & $\mathbf{9}$ & $\mathbf{1 0}$ & $\mathbf{1 1}$ \\
\hline $\mathrm{Z}_{0 \mathrm{j}}$ & 0,52 & 0,39 & 1,71 & 1,62 & $-0,52$ & 1,07 & 0,44 & 1,04 & 0,61 & 1,20 & 1,22 \\
\hline \multirow{2}{*}{ Период } & \multicolumn{10}{|c|}{ Показатели } \\
\cline { 2 - 12 } & $\mathbf{1 2}$ & $\mathbf{1 3}$ & $\mathbf{1 4}$ & $\mathbf{1 5}$ & $\mathbf{1 6}$ & $\mathbf{1 7}$ & $\mathbf{1 8}$ & $\mathbf{1 9}$ & $\mathbf{2 0}$ & \multicolumn{2}{|c|}{0,91} \\
\hline $\mathrm{Z}_{0 \mathrm{j}}$ & 0,00 & 1,05 & 1,30 & 2,12 & 0,38 & 1,06 & 1,16 & 1,08 & 1,14 & 0,91 \\
\hline
\end{tabular}

Таблица 3. Матрица расчета расстояния между отдельными наблюдениями (период) и вектором-эталоном

Источник: рассчитано автором 


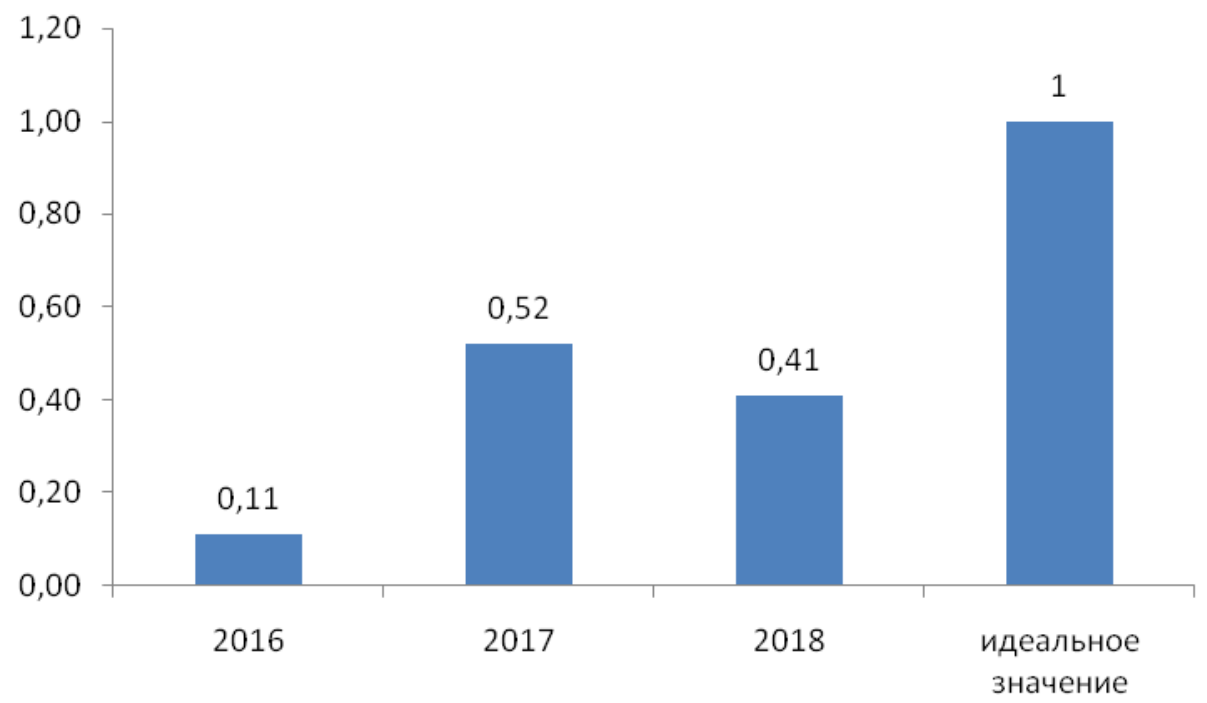

Puc. 1. Динамика таксономического показателя эффективности работы ПАО «Распадская» в 2016-2018 гг. Источник: рассчитано автором

менее эффективно в 2016 г.- 0,11, соответственно. Ухудшение интегрального таксономического показателя в 2018 г. было обусловлено ростом долговой нагрузки компании, увеличением уровня инфляции, повышением энергоемкости производства и снижением производительности труда.

Таким образом, критический анализ зарубежных и отечественных подходов к оценке уровня эффективности развития предприятий угледобывающей отрасли, позволил уточнить существующие наработки исследователей с точки зрения формирования системы показателей, учитывающей финансовую, экономическую, социальную, производственно-техническую и экологическую составляющие работы предприятия. Преимуществами предложенных показателей являются: охват всех сторон деятельности компании, простота их расчета, отсутствие субъективизма и наличие доступной информации для их оценки. В свою очередь выбранный методологический подход на основе использо- вания таксономического показателя позволяет получить комплексную оценку, учитывающую направление и масштабы изменений в процессе деятельности предприятия. Более того, предложенная методика оценки эффективности развития угледобывающего предприятия может быть скорректирована с учетом специфики деятельности компании путем добавления новых (например, курс валют - если предприятие ориентировано на экспорт) или исключения имеющихся показателей. В нашей работе «Анализ классификаций факторов устойчивого развития угледобывающих предприятий» мы уже отмечали набор факторов, которые возможно и правильно включать в анализ угледобывающих предприятия по направлению устойчивого развития [15]. В будущих работах по тематике устойчивого развития, авторы планируют апробировать на более репрезентативной выборке предприятий МСК и систематизировать наработанные заключения и результаты.

\section{Библиографический список}

1. Казаков А. В., Колышкин А.В. Разработка моделей прогнозирования банкротства в современных российских условиях // Вестник Санкт-Петербургского университета. Экономика. 2018. Т. 34. Вып.2. С. 241-266.

2. Федорова Е.А., Довженко С.Е. Разработка методики оценки финансовой устойчивости организаций отрасли обрабатывающей промышленности // Финансы и кредит. 2015. № .25. С. 2-10.

3. Федорова Е. А., Тимофеев Я.В. Разработка моделей прогнозирования банкротства российских предприятий для отраслей строительства и сельского хозяйства // Финансы и кредит. 2015. № .32. С. 2-10.

4. Butkus M., Žakaré S., Cibulskiené D. Bankroto diagnostikos modelis ir jo pritaikymas bankroto tikimybei Lietuvos imonėse prognozuoti. URL: https://ejournals.vdu.lt/index.php/applied-economics/article/view/169. (дата обращения: 25.08.2019). 
5. Ткач Е. С., Ханафиева Ю.Д., Чекушина И.А. Модель оценки вероятности банкротства в нефтегазовой отрасли. URL: ftp://ftp.repec.org/opt/ReDIF/RePEc/rnp/ppaper/ch1641.pdf. (дата обращения: 25.08.2019).

6. Жданов В.Ю., Афанасьева О.А. Разработка модели диагностики риска банкротства для авиапредприятий. URL: https://cyberleninka.ru/article/n/razrabotka-modeli-diagnostiki-riska-bankrotstva-dlyaaviapredpriyatiy. (дата обращения: 25.08.2019).

7. Yan C., Dai H., Guo W. Evaluation of Ecological Environmental Quality in a Coal Mining Area by Modelling Approach // Sustainability. - 2017. - № 9 (1265). - pp. 1-13.

8. Lins C., Horwitz E. Sustainability in the mining sector. URL: http://www.fbds.org.br/IMG/pdf/doc-295.pdf (дата обращения: 27.08.2019).

9. A Review on Indicators of Sustainability: for the mineral extraction industries / Eds. Roberto C. Villas Boas, Débora Shields, Šlavko Solar, Paul Anciaux, Güven Önal Rio de Janeiro: CETEM/MCT/ CNPq/CYTED/IMPC, 2005 230p.

10. Комиссарова M.A. Стратегическое управление предприятиями угледобывающей промышленности восточного Донбасса: дисс. докт. экон. наук. 08.00.05 - Экономика и управление народным хозяйством: экономика, организация и управление предприятиями, отраслями, комплексами - промышленность / ФГБОУ ВПО «Ростовский государственный экономический университет (РИНХ)». Ростов-на-Дону, 2014. - 270с.

11. Дубров А.М. Многомерные статистические методы: ученик / А.М. Дубров, В.С. Мхитарян, Л.И. Трошин.М.: Финансы и статистика, 2000.- 352 с.

12. Официальный сайт ПАО «Распадская». Годовые отчеты. URL: http://www.raspadskaya.ru/disclosure/annual/ (дата обращения: 28.08.2019).

13. Таразанов И.Г. Итоги работы угольной промышленности России за январь-декабрь 2017 года// Уголь.2018. - № 3.- С. 58-73

14. Таразанов И.Г. Итоги работы угольной промышленности России за январь-декабрь 2018 года // Уголь.2019. - № 3.- С. 64-79

15. Лютягин Д.В., Сорокина В.В. Анализ классификаций факторов устойчивого развития угледобывающих предприятий. «Финансовая экономика» всероссийский научно-аналитический журнал № 9-2019 г. 